\title{
Agronegócio globalizado no MATOPIBA maranhense: análise da especialização regional produtiva da soja
}

La agroindustria globalizada en Matopiba Maranhense: análisis de la especialización regional de la producción de soja

Globalized agribusiness in the Matopiba Maranhense: analysis of the soybean production regional specialization

Le Sector Agroalimentaire mondialisée à Matopiba Maranhense : analyse de la espécialisation régionale de la production de soja.

\section{Ricardo Castillo, Adielson Correia Botelho e Matheus Dezidério Busca}

\section{(2) OpenEdition}

\section{Journals}

\section{Edição electrónica}

URL: https://journals.openedition.org/espacoeconomia/19325

DOI: 10.4000/espacoeconomia.19325

ISSN: 2317-7837

\section{Editora}

Núcleo de Pesquisa Espaço \& Economia

\section{Refêrencia eletrónica}

Ricardo Castillo, Adielson Correia Botelho e Matheus Dezidério Busca, «Agronegócio globalizado no MATOPIBA maranhense: análise da especialização regional produtiva da soja », Espaço e Economia [Online], 21 | 2021, posto online no dia 09 julho 2021, consultado o 17 julho 2021. URL: http:// journals.openedition.org/espacoeconomia/19325 ; DOI: https://doi.org/10.4000/espacoeconomia. 19325

Este documento foi criado de forma automática no dia 17 julho 2021.

\section{c) (1) (2)}

Espaço e Economia - Revista brasileira de geografia econômica est mise à disposition selon les termes de la licence Creative Commons Attribution - Pas d'Utilisation Commerciale - Partage dans les Mêmes Conditions 4.0 International. 


\section{Agronegócio globalizado no MATOPIBA maranhense: análise da especialização regional produtiva da soja}

La agroindustria globalizada en Matopiba Maranhense: análisis de la especialización regional de la producción de soja

Globalized agribusiness in the Matopiba Maranhense: analysis of the soybean production regional specialization

Le Sector Agroalimentaire mondialisée à Matopiba Maranhense : analyse de la espécialisation régionale de la production de soja.

Ricardo Castillo, Adielson Correia Botelho e Matheus Dezidério Busca

\section{Introdução}

1 A soja é a principal cultura praticada no território brasileiro em termos de extensão, tendo ocupado quase 35 milhões de hectares (PAM-IBGE), exportado 72,6\% do total de grãos produzidos e gerado US\$ 40,9 bilhões em divisas (AGROSAT) em 2018. Os principais estados produtores são o Mato Grosso, com 27,1\% da área plantada e 26,8\% da quantidade produzida, seguido pelo Rio Grande do Sul, com 16,4\% e 14,9\%, Paraná, com $15,4 \%$ e $16,1 \%{ }^{1}$ e Goiás, com 9,5\% e 9,7\%, respectivamente (PAM-IBGE). Juntos, esses quatro estados responderam por $68,4 \%$ da área plantada e $67,5 \%$ da quantidade produzida de soja em 2018 (PAM-IBGE) no país.

2 Não obstante o peso esmagador desses números e a hegemonia das macrorregiões Centro-Oeste e Sul do país no complexo soja (ABIOVE), uma outra porção do território brasileiro, conhecida como MATOPIBA, região geoeconômica e de planejamento dos Cerrados do Norte/Nordeste (BERNARDES, 2009; ALVES, 2015), que envolve, parcial ou integralmente, os estados do Maranhão, Tocantins, Piauí e Bahia, vem se destacando na 
atividade por seu forte dinamismo desde a década de1990, com expressivo crescimento a partir dos anos 2000 .

3 Entre 1990 e 2018, os estados integrantes do MATOPIBA cresceram exponencialmente em termos de área plantada de soja, com destaque para o Piauí (45.584\%) e o Maranhão (6.054\%), muito acima das regiões mais consolidadas, como Rio Grande do Sul (162\%), Paraná (236\%), Goiás (328\%) e Mato Grosso (607\%), no mesmo período (PAM-IBGE). Trata-se de uma promissora fronteira em expansão para as ações do agronegócio globalizado.

No intuito de contribuir para a imprescindível discussão sobre regionalização e dinâmica atual de expansão da agricultura intensiva no território brasileiro, propomos dois objetivos para este artigo: 1) discutir a dinâmica da sojicultura no MATOPIBA e 2) identificar as regiões produtivas (SANTOS, 1985, p. 71-72) do agronegócio da soja nos Cerrados maranhenses. Como pano de fundo e motivação para este artigo, lançamos a hipótese geral - que não será demonstrada aqui - de que o acelerado ritmo de expansão da sojicultura moderna no MATOPIBA, mais do que nos cerrados do Centro-Oeste, provocou mudanças drásticas no uso dos territórios municipais envolvidos, em favor das grandes empresas do agronegócio, gerando conflitos e resistências de diversas naturezas e intensidades.

5 Foram levantados dados sobre a produção de soja e infraestruturas logísticas em diversas bases, tais como Produção Agrícola Municipal, Censo Agropecuário e Informações Ambientais do Instituto Brasileiro de Geografia e Estatística; Companhia Nacional de Abastecimento do Ministério da Agricultura, Pecuária e Abastecimento; Departamento Nacional de Infraestrutura de Transporte do Ministério dos Transportes; Plataforma Trase (Transparent Supply Chains for Sustainable Economies), além de revistas e jornais da grande mídia. A bibliografia utilizada priorizou autores com reconhecida experiência e trabalhos de campo na região, que discutem a regionalização fundamentada na divisão territorial do trabalho, numa perspectiva crítica. 0 geoprocessamento e a cartografia foram realizados através do software SIG QGIS 3.12.

6 Além desta introdução e de uma conclusão, o texto está dividido em três partes. $\mathrm{Na}$ primeira, apresentamos um breve histórico e um perfil da região do MATOPIBA e sua institucionalização, isto é, sua mudança de status para região de planejamento, com o objetivo de contextualizar a sua porção maranhense, almejando estabelecer uma relação dialética entre a parte e o todo. Em seguida, com base na teoria das múltiplas formas regionais, discutimos a porção do estado do Maranhão pertencente ao MATOPIBA. Finalmente, na terceira parte, analisamos a microrregião Gerais de Balsas e levantamos alguns argumentos que sustentam a hipótese de considerá-la a principal região produtiva (SANTOS, 1985) do agronegócio da soja (FACCIN; CASTILLO, 2019), do MATOPIBA maranhense.

\section{Formação regional do MATOPIBA}

7 Considerada a grande fronteira agrícola do território brasileiro na atualidade, a região geoeconômica ${ }^{2}$ (GARAGORRY et al. 2009; XAVIER, 2019) dos Cerrados do Centro-Norte (ALVES, 2009) começa a desenvolver uma agropecuária modernizada a partir da segunda metade da década de $1980^{3}$ (XAVIER, 2019, p. 5), e desponta na década de 1990 como importante área de expansão do agronegócio globalizado (ELIAS, 2011; 2013). Inicialmente batizada como MAPITO, envolvia o sul e leste do Maranhão, o sudoeste do 
Piauí e o leste do Tocantins, e foi reconhecida como tal pelo Governo Federal, ao menos desde $2013^{4}$. Antes disso, porém, o oeste da Bahia já tinha sido incorporado como parte da região geoeconômica por diversos pesquisadores, tais como Bernardes (2009) e Alves (2009), consagrando, no meio acadêmico, o acrônimo BAMAPITO.

Um dos principais indicadores utilizados na delimitação do BAMAPITO (mapa 1) foi a presença do vasto Domínio dos Chapadões Tropicais Interiores com Cerrados e MatasGaleria (AB'SABER, 2003), cujos solos são predominantemente ácidos, induzindo ao elevado consumo de corretivos de pH e de fertilizantes químicos (SANO et al., 2007). Por outro lado, a morfologia predominante é altamente favorável à mecanização das culturas, facilitando o uso massivo de tecnologias avançadas em grande escala, prestando-se perfeitamente às grandes monoculturas e favorecendo a manutenção e o aprofundamento da concentração fundiária.

Mapa 1. Brasil, Matopiba e Unidades da Federação. Bioma Cerrado.

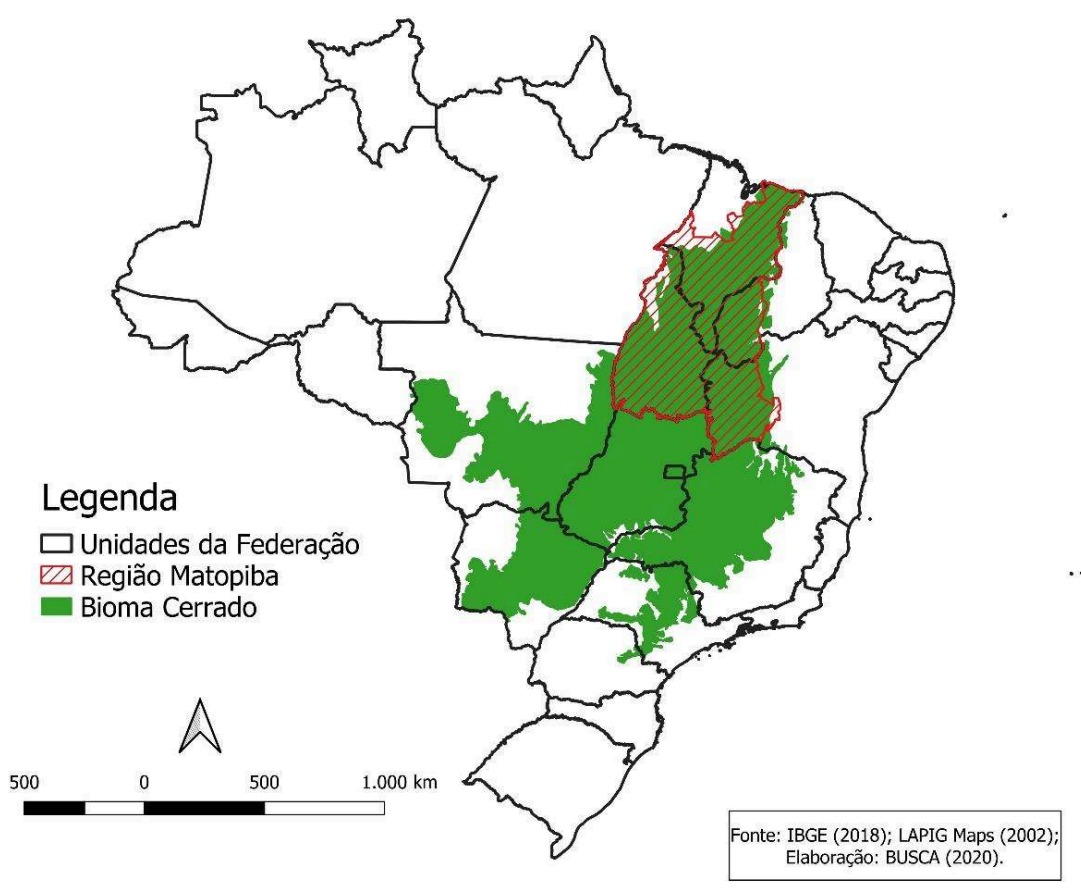

O movimento de ocupação do domínio dos Cerrados começou de maneira mais sistemática pela macrorregião Centro-Oeste, com o apoio direto do Estado através de programas de colonização, incentivos fiscais, crédito rural, desenvolvimento de cultivares adaptadas às suas condições naturais (soja, milho, algodão, cana-de-açúcar dentre outros), investimentos em equipamentos de armazenagem e em infraestruturas de circulação. $O$ modelo da agricultura científica globalizada (SANTOS, 2000) adotado na região geoeconômica do BAMAPITO é herdeiro da dinâmica desenvolvida no CentroOeste e, possivelmente, também daquela praticada precocemente no oeste da Bahia.

Dadas as características naturais dessa porção do território brasileiro, somadas a investimentos em infraestruturas do Governo Federal e dos quatro estados envolvidos, o BAMAPITO foi se consolidando como importante fronteira de expansão da agricultura intensiva, praticada em grandes propriedades e voltada para a produção de commodities agrícolas, principalmente soja e algodão, além de acolher frações do capital financeiro ávidas por ganhos especulativos com produtos agrícolas e com a própria terra (SOUZA; 
SILVA, 2019). As principais características deste modelo agrícola hegemônico são extensas monoculturas, uso intensivo de insumos químicos e biotecnológicos, maquinário equipado com tecnologias digitais, participação de grandes empresas nacionais e transnacionais do agronegócio, consumo de serviços especializados agronômicos, jurídicos, contábeis, informacionais e logísticos, participação massiva do capital financeiro na agropecuária, constituindo um fenômeno que ficou conhecido como land grabbing (BORRAS Jr., KAY, GÓMEZ \& WILKINSON, 2012). Todas essas características, em diferentes combinações e intensidades em cada lugar, são necessárias para alcançar elevados níveis de competitividade (CASTILLO; BERNARDES, 2019) e, desse modo, participar dos mercados globalizados.

11 Em 2015, o Governo Federal, através da Empresa Brasileira de Pesquisa Agropecuária Embrapa Territorial, institucionaliza ${ }^{5}$ a região geoeconômica, rebatizando-a como MATOPIBA, e cria o seu Plano de Desenvolvimento Agropecuário (PDA MATOPIBA) 6 . Curiosamente, nesta nova versão, o estado do Tocantins passa a ser incluído na sua íntegra ${ }^{7}$.

O reconhecimento oficial confere a esta porção do território brasileiro o estatuto de região de planejamento ${ }^{8}$ (CASTILLO; BERNARDES, 2019), estabelecendo o marco legal indispensável a uma aliança mais consolidada entre o Estado, as grandes empresas do agronegócio e o capital financeiro, na expansão da fronteira agrícola moderna, em detrimento dos agentes do circuito inferior da economia agrária (ELIAS, 2011), como vem sendo constatado em pesquisas recentes (ALVES, 2015; ASSUMPÇÃo E LIMA, 2019; ALMEIDA; SODRÉ; MATTOS JR., 2019; SOUZA e PEREIRA, 2019; XAVIER, 2019).

13 A análise do Plano de Desenvolvimento Agropecuário do MATOPIBA (2015) permite concluir que o seu principal propósito foi o de fortalecer e expandir as regiões produtivas do agronegócio (ELIAS, 2011; 2013), isto é, os compartimentos regionais decorrentes do aprofundamento da divisão territorial do trabalho no âmbito da agricultura intensiva em capital, precipitando uma especialização regional produtiva ${ }^{9}$, em paralelo ao aumento de fluxos materiais e informacionais, reestruturando as relações campo-cidade (ELIAS, 2013; CASTILLO et al., 2016) e permitindo densas interações espaciais (CORRÊA, 2016), nas escalas nacional e mundial. As regiões produtivas do agronegócio respondem à assertiva de Santos (1988), para quem

14 Na definição atual das regiões, longe estamos daquela solidariedade orgânica que era o próprio cerne da definição do fenômeno regional. 0 que temos hoje são solidariedades organizacionais. As regiões existem porque sobre elas se impõem arranjos organizacionais, criadores de coesão organizacional baseada em racionalidades de origens distantes, mas que se tornam o fundamento da existência e da definição desses subespaços (SANTOS, 1994, p. 57)

15 A dinâmica do MATOPIBA, particularmente de suas regiões produtivas do complexo soja mais consolidadas, decorre de uma regulação híbrida que envolve, principalmente, por um lado, ações dos governos estaduais, que visam fomentar o desenvolvimento econômico através de políticas públicas, incentivos fiscais e investimentos em infraestrutura logística e, por outro, nas estratégias das grandes empresas do agronegócio globalizado, tais como Bunge, Cargill, ADM, Amaggi, Louis Dreyfus Commodities, Grupo Horita, Adecoagro, Cofco, Gavilon, Agrograin, Multigrain, Agrex, Agrinvest, CHS, Glencore, Risa, Oleoplan e Fiagril (TRASE) dentre outras - que controlam diversas etapas dos circuitos espaciais produtivos (SANTOS; SILVEIRA, 2001; 
CASTILLO; FREDERICO, 2010a), sobretudo do complexo soja. Essa situação aprofunda antigas e engendra novas desigualdades sociais, econômicas e geográficas na região.

\section{A porção maranhense do MATOPIBA}

Diversos autores (CASTILLO, 2015; CASTILLO, ELIAS, PEIXINHO, BÜHLER, PEQUENO; FREDERICO, 2016; CASTILLO \& BERNARDES, 2019) advogam que o processo de regionalização decorre de uma relação dialética que envolve diversas formas regionais e múltiplas escalas territoriais, que se transformam juntas, em permanente interação. De acordo com essa proposição, a dinâmica regional decorre das relações complementares e contraditórias estabelecidas entre a região natural, a região tradicional, a região de planejamento, a região produtiva ${ }^{10}$ e os territórios, estes compreendidos como compartimentos político-jurídico-institucionais do espaço geográfico (GOTTMANN, 1975).

No caso da porção maranhense do MATOPIBA (mapa 2), são múltiplos os compartimentos geográficos diretamente envolvidos em suas transformações ao longo das últimas três décadas, tais como a formação socioespacial brasileira (SANTOS, 1977), o estado do Maranhão, a região natural do Cerrado e suas fitofisionomias (RIGONATO; ALMEIDA, 2003), os territórios municipais envolvidos, a região produtiva nucleada pela microrregião Gerais de Balsas e, por fim, a própria região de planejamento do MATOPIBA.

Mapa 2. Estado do Maranhão. Microrregiões geográficas pertencentes ao MATOPIBA

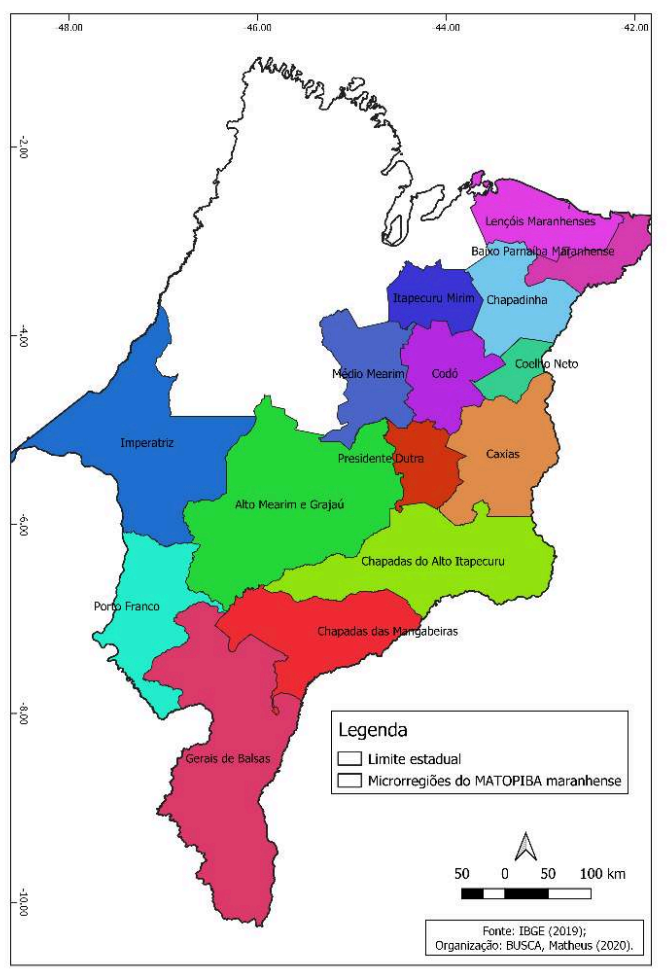

No tocante ao território maranhense, o estado é apenas o nono maior produtor da soja nacional, com 2,75 milhões de toneladas em 2018 (2,3\% do total), mas é o segundo maior 
do MATOPIBA $(19,4 \%)$ em quantidade produzida, atrás somente da Bahia $(44,4 \%)$ (PAMIBGE), como pode ser observado no mapa 3.

Mapa 3. Brasil. Quantidade produzida de soja (toneladas) e participação da soja de cada estado no total do país (\%). 2018

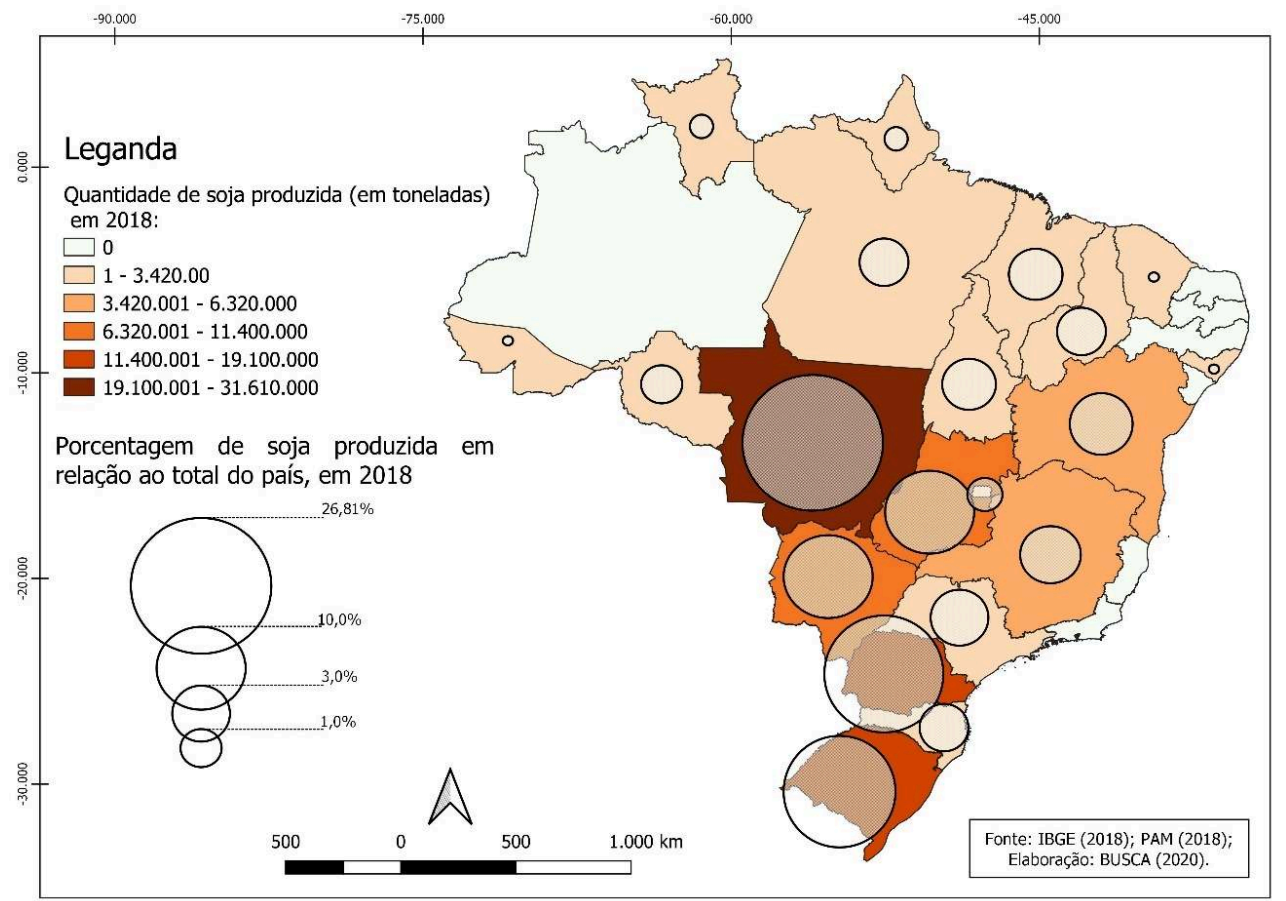
estimulado, em grande medida, por políticas públicas como Programa Corredor de Exportação Norte e PRODECER ${ }^{11}$ III (FERREIRA, M. G., 2008; FERREIRA, A. J., 2008; PALUDZYSZYN FILHO, 1995).

Além dos Planos e Programas criados para atrair investimentos produtivos, de linhas especiais de crédito oficial, da pesquisa agronômica desenvolvida por instituições públicas, como a Embrapa Soja e a Embrapa Cerrados, do baixo custo de aquisição e arrendamento de terras em comparação com outras regiões, outro fator importante para a viabilidade da produção de grãos em larga escala nos Cerrados é a logística, um dos óbices mais importantes a serem superados, considerando sua complexidade técnica e regulatória e o volume dos recursos envolvidos (FACCIN; CASTILLO, 2019). De acordo com Oliveira (2006), o conjunto de obras de infraestruturas concluídas ou planejadas para diversas porções do bioma Cerrado direcionou os investimentos das multinacionais do agronegócio que passaram a buscar localizações estratégicas, redesenhando, desse modo, o sistema de circulação de commodities para exportação. Nessa conjuntura, vários corredores de transporte vão sendo estruturados no país com vistas ao escoamento da produção agrícola, dentre os quais se destaca o Programa Corredor de Exportação Norte (PCEN), envolvendo o sul do estado do Maranhão, cujos produtos seguem de Balsas até Imperatriz de caminhão, num percurso de $400 \mathrm{~km}$, e de lá seguem pela ferrovia Norte-Sul até o porto de São Luís (mapa 4). 
Mapa 4. MATOPIBA. Equipamentos selecionados e principais rodovias para o escoamento da soja, 2017

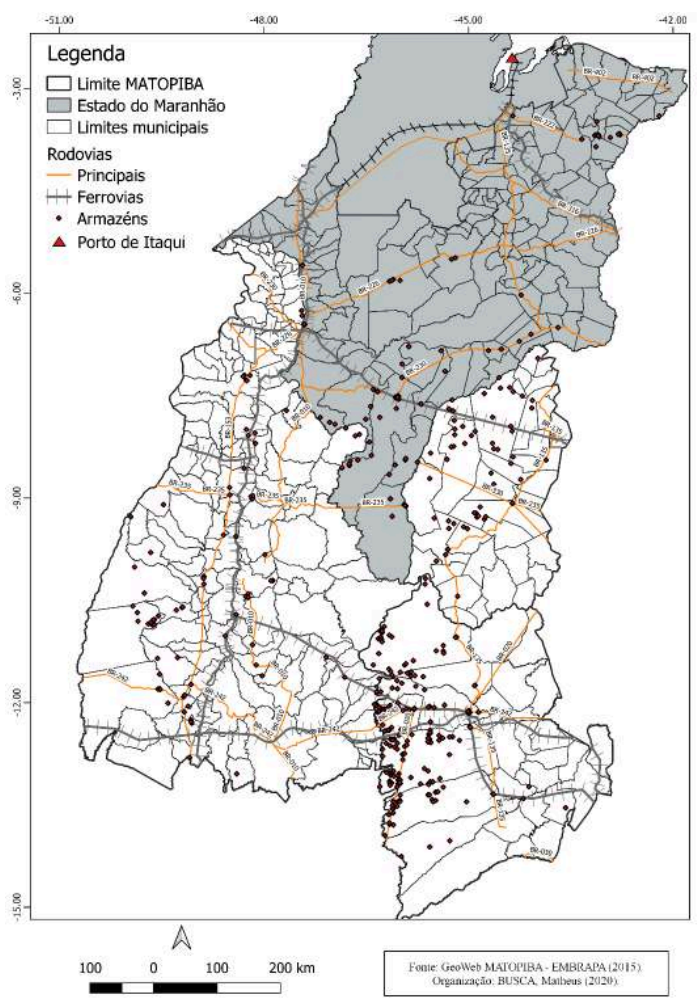

21 O sistema de escoamento que compreende o PCEN é composto por vários corredores de transporte envolvendo os modais rodoviário, hidroviário e ferroviário, que se conectam aos portos nordestinos (ALVES, 2006). Constitui-se, nos casos da produção de soja no Maranhão e no Piauí, das rodovias BR 230 e BR 010 até o município maranhense de Porto Franco, importante entroncamento da ferrovia Norte-Sul, de onde segue para Açailândia, onde se conecta com a Estrada de Ferro Carajás - principal eixo de transporte do Corredor, que leva ao porto exportador de Itaqui (MA) (ALVES, 2006), cujo terminal de grãos foi inaugurado em 2015, transformando-o no principal porto exportador de grãos das regiões Norte e Nordeste (SECEX-MDIC).

A implantação de nós logísticos (BRAGA; CASTILLO, 2013), os serviços de manutenção de rodovias estratégicas, os investimentos em pesquisa agronômica, o oferecimento de crédito agrícola, os benefícios fiscais para a implantação de agroindústrias são indicadores de que não se pode falar do processo de modernização da soja ou implantação e expansão do agronegócio sojícola globalizado no território maranhense sem a participação direta do Estado, em suas diversas escalas.

No estado, a Mesorregião Sul Maranhense se consolidou como a mais importante produtora de soja a partir da década de 1990, com destaque para o município de Balsas. As políticas públicas em parceria com a iniciativa privada foram responsáveis pelo crescimento acelerado da produção de soja no município de Balsas e, posteriormente, sua expansão para outras regiões do estado, a exemplo do Leste Maranhense, onde o município de Brejo se apresenta como principal produtor, tanto em área plantada, quanto em quantidade produzida (PAM-IBGE) (mapa 5) ${ }^{12}$. 
Mapa 5. Porção Maranhense do MATOPIBA. Área plantada de soja, 1990, 2000, 2010, 2018
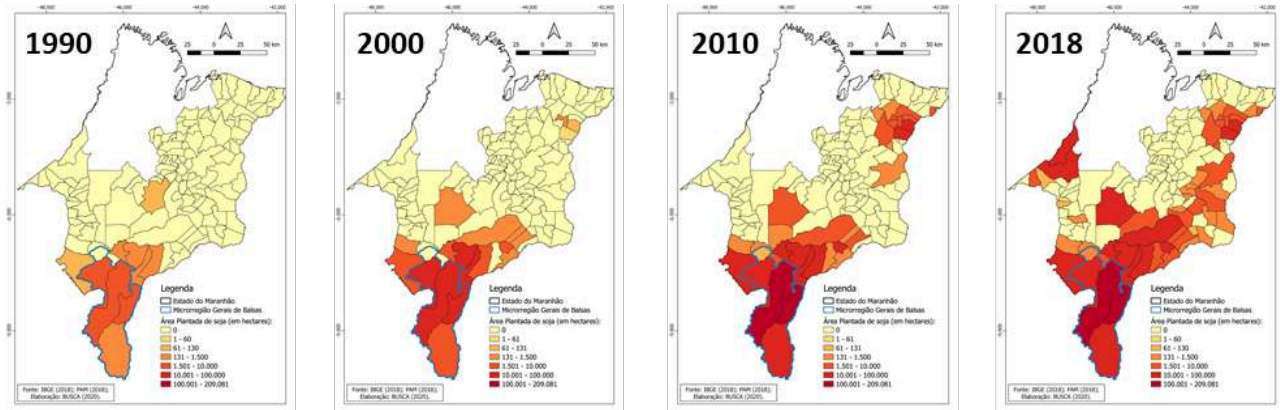

Fonte: Produção Agrícola Municipal do IBGE. Organização e cartografia: BUSCA, Matheus D., 2020

O mapa 6, por seu turno, objetiva demonstrar o grau de concentração da produção de soja, como indicador do aprofundamento da divisão territorial do trabalho e da especialização regional produtiva da soja no Maranhão.

Mapa 6. Porção Maranhense do MATOPIBA. Participação da soja no total das culturas temporárias e permanentes, 1990, 2000, 2010, 2018
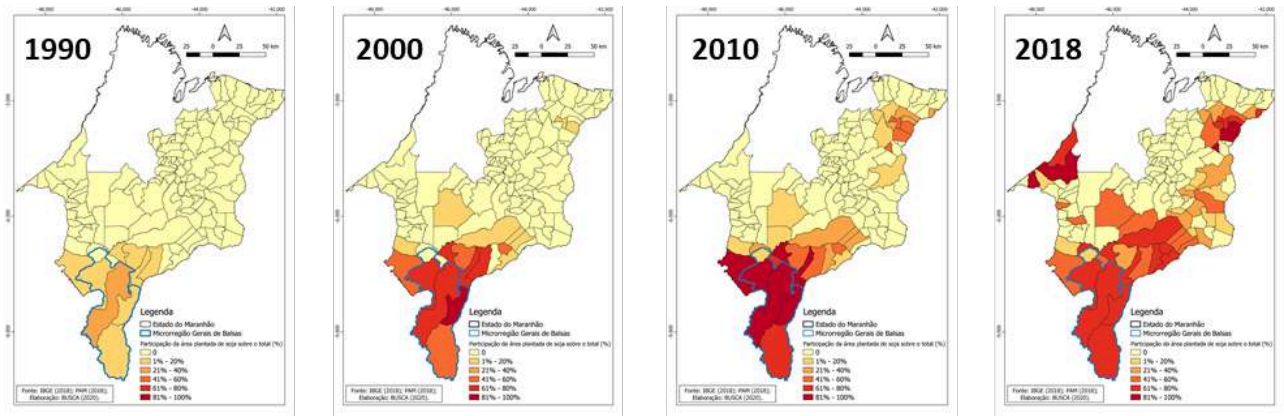

Fonte: Produção Agrícola Municipal do IBGE. Organização e cartografia: BUSCA, Matheus D., 2020

Pode-se observar no mapa 6 que, ao longo do período retratado, houve uma nítida concentração da produção de soja no sul do Estado nas décadas de 1990 e 2000, seguida por uma configuração em quatro áreas de especialização produtiva principais nas microrregiões de Gerais de Balsas (destacada no mapa), Chapada das Mangabeiras, Chapadinha e Imperatriz.

\section{Região Produtiva do Agronegócio da Soja na Microrregião Geográfica Gerais de Balsas /MA}

A microrregião Gerais de Balsas foi o primeiro subespaço do Maranhão a cultivar a soja nos moldes da agricultura científica globalizada e assumiu o protagonismo no processo de regionalização produtiva. O Município de Balsas chegou a ser o terceiro maior produtor de soja de toda a Região Nordeste em 2013 e 2014, tendo caído para a sétima posição entre 2016 e 2018 (PAM-IBGE), sem nunca ter deixado de crescer em termos absolutos.

29 A distribuição da sojicultura na porção maranhense do MATOPIBA é fortemente concentrada na microrregião Gerais de Balsas, que respondeu por $53,2 \%$ da área 
plantada de soja (492.716 ha) em 2018, seguida de longe pelas microrregiões Chapada das Mangabeiras (18,6\%), Chapadinha (7\%) e Imperatriz (6\%) (PAM-IBGE).

Trata-se aqui do fenômeno da especialização regional produtiva, decorrente do aprofundamento da divisão territorial do trabalho, que expressa uma sofisticada geografia praticada pelas grandes empresas, na busca pelas melhores condições, materiais e imateriais, para a localização de seus investimentos, guiadas pelo imperativo da competitividade (SANTOS, 1996; CASTILLO et. al. 2016).

31 Além do aumento exponencial da área plantada de soja na microrregião Gerais de Balsas que, segundo dados da Produção Agrícola Municipal do IBGE, passou de 10.900 ha em 1990 para 492.716 ha em 2018, merece destaque a dinâmica do rendimento médio da produção que, segundo a mesma fonte, na década de 1990 foi de $1.778 \mathrm{Kg} / \mathrm{ha}$, passando para $2.638 \mathrm{Kg} / \mathrm{ha}$ na década seguinte, e para $2.850 \mathrm{Kg} / \mathrm{ha}$ entre 2010 e 2018 (com exceção do ano de $2016^{13}$ ). Isso demonstra um crescimento vertical da produção ${ }^{14}$, fruto da adoção de um modelo de agricultura intensiva, dependente de uso massivo de insumos químicos (corretivos, fertilizantes, agrotóxicos) e biotecnológicos (cultivares mais produtivas e adaptadas a condições edafoclimáticas específicas), maquinário (inclusive com tecnologia digital embarcada), assistência técnica agronômica, mecânica e outros serviços sofisticados, para manter um patamar de competitividade estabelecido pelos mercados globalizados (gráfico 1).

Gráfico 1. Microrregião Geográfica Gerais de Balsas (MA). Evolução da área plantada, quantidade produzida e rendimento médio da produção de soja (em grão) 1995 - 2018

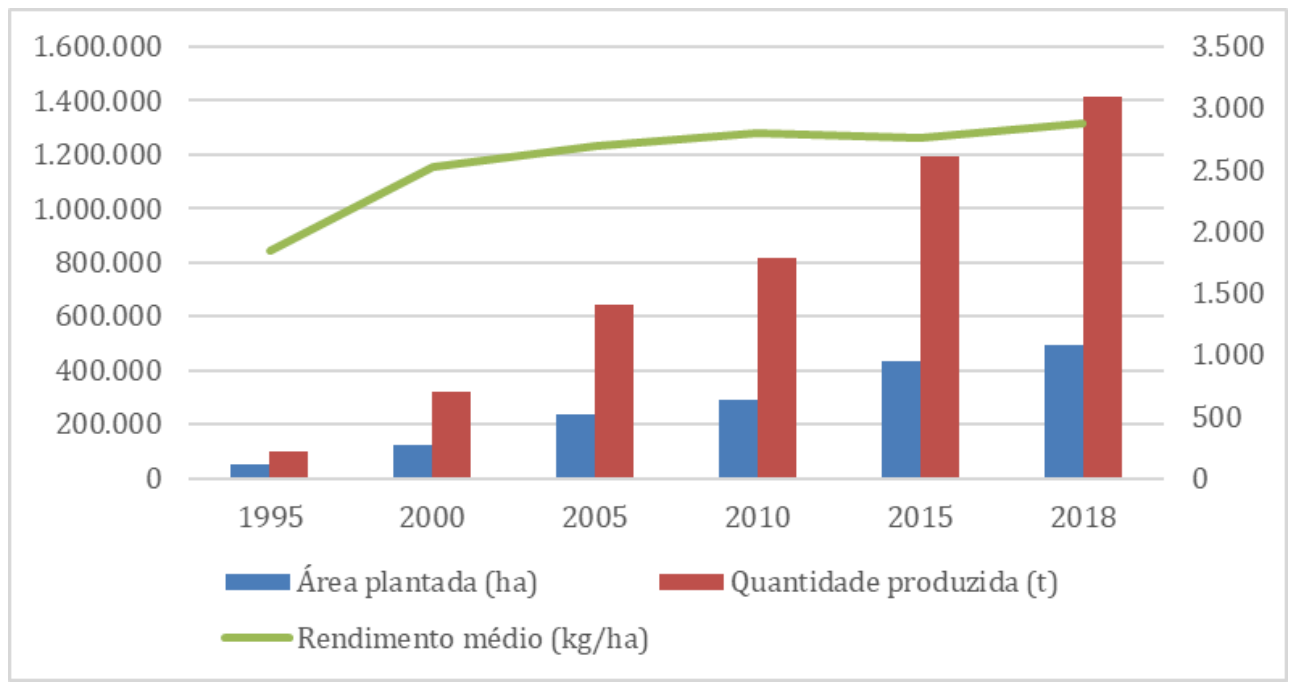

Fonte: IBGE - Produção Agrícola Municipal. Organização: BOTELHO, A. C., 2020

O avanço do crescimento vertical da produção está associado, além dos fatores já mencionados, ao adensamento de uma rede urbana funcional ao agronegócio, bem como à conversão ou adaptação de algumas cidades ao atendimento das demandas produtivas agrícolas especializadas (ELIAS, 2011), tais como comercialização de insumos químicos e maquinários, crédito agrícola, assistência técnica especializada, armazenamento, escritórios de representação de empresas do agronegócio, agroindústrias, serviços de transporte (agentes dos circuitos superior e inferior da economia urbana) e logística, associações setoriais, feiras agropecuárias, dentre outros, além dos serviços de consumo pessoal voltados a uma classe média gerencial, vinculada ao agronegócio globalizado. Como afirma Elias (2007, p. 118), "quanto mais modernas se 
tornam essas atividades [do agronegócio globalizado], mais urbana se torna a sua regulação".

Aliado às grandes empresas, o Estado é imprescindível no processo de especialização regional produtiva, oferecendo benefícios fiscais e materiais, criando cursos funcionais ao agronegócio em Universidades federais e estaduais, apoiando Institutos de pesquisa agropecuária, investindo em infraestruturas logísticas.

As mudanças do uso do território em favor do agronegócio globalizado têm, como consequências, a valorização e a especulação fundiária regional, o deslocamento ou expulsão de populações tradicionais e da agricultura familiar, o aumento da urbanização da população e do êxodo rural na Microrregião Gerais de Balsas (Gráfico 2), ainda que o Maranhão, segundo dados do IBGE, continue sendo o estado com a maior proporção de população rural do país. Outra situação característica da Região Produtiva de Balsas diz respeito ao desemprego estrutural no campo provocado pela expansão do cultivo de soja, uma vez que tal atividade é altamente mecanizada/informatizada, desde o plantio até a colheita. Inferimos, também, que a população da região se urbanizou devido à chegada de novos agentes econômicos relacionados às atividades do agronegócio globalizado, fato este que atraiu grande número de pessoas em busca de oportunidades de trabalho na cidade.

Gráfico 2. Microrregião Gerais de Balsas/MA. Situação domiciliar da população (1991 - 2010)

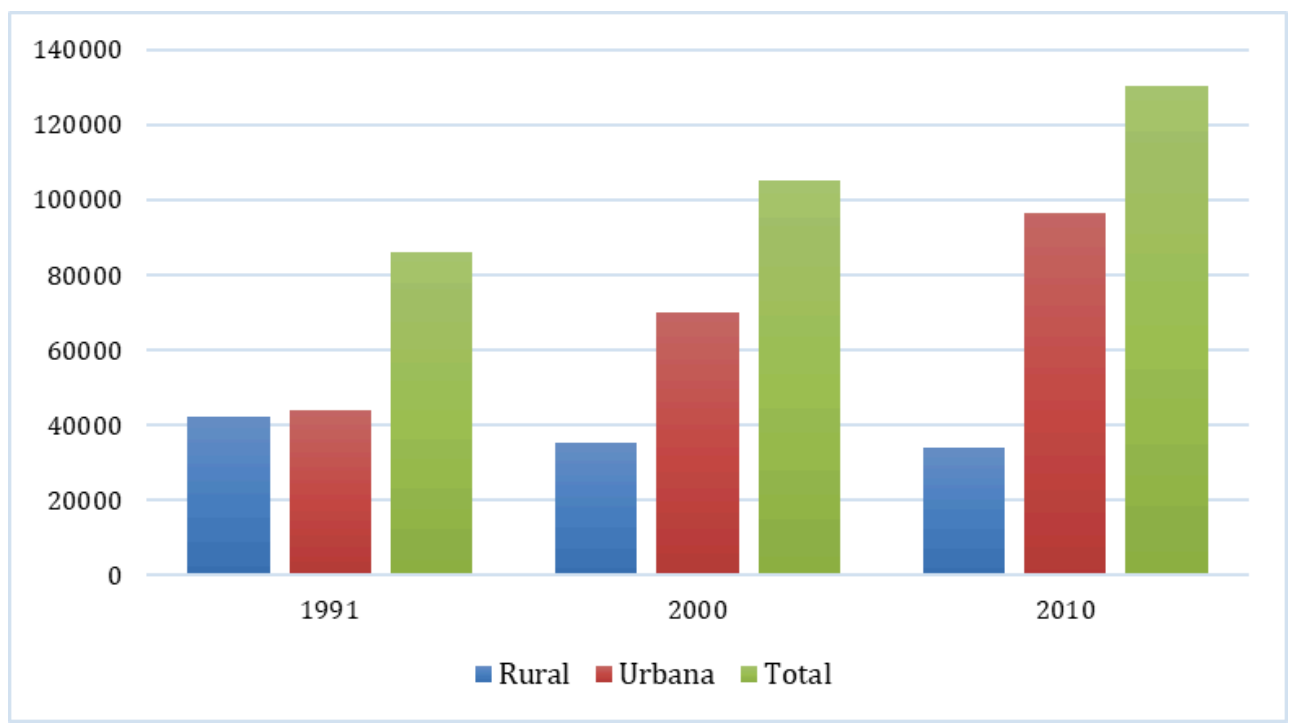

Fonte: IBGE - Censo Demográfico. Organização: BOTELHO, A. C., 2020

O município de Balsas, o mais importante da microrregião, acentua ainda mais a concentração de pessoas em atividades urbanas, inclusive aquelas que atuam em empresas agrícolas. Nele, o crescimento da população total, em duas décadas, segundo os Censos Demográficos de 1991 e 2010, mais que dobrou, e a população urbana passou de $73,5 \%$ para $87 \%$ no período, acima da taxa de urbanização brasileira que foi de $84,4 \%$ em 2010 (IBGE). Balsas ocupa o terceiro lugar no ranking do PIB estadual, atrás apenas de São Luís e Imperatriz, e é o mais importante município maranhense em valor adicionado da agropecuária (IMESC-SEPE-MA). Vale ainda ressaltar que Balsas detém a quinta maior renda per capita do estado, calculado em R\$32.142,30 em 2017, atrás de Tasso Fragoso e Santo Antonio dos Lopes (ambos com PIB per capita acima de R\$ 100 
mil), Davinópolis e Sambaíba (IMESC-SEPE-MA), e pouco à frente do Brasil, que fechou 2017 com $\mathrm{R} \$ 31.833,50$ (IBGE). aumentou significativamente. No gráfico 3 , observa-se um crescimento exponencial das empresas classificadas como "Agricultura, pecuária, produção florestal, pesca e aquicultura", a exemplo da Cargill, Bunge, Risa e Agroserra. Também merece destaque o setor de "Transporte, armazenagem e correio", envolvendo silos especializados no armazenamento e conservação de grãos, notadamente soja e milho, e transporte rodoviário de carga. Pode-se observar também o crescimento e estabilização das empresas e instituições prestadoras de serviços técnicos, científicos e de educação e outras imprescindíveis para a sustentação da agricultura científica globalizada. 
Gráfico 3. Microrregião Gerais de Balsas. Empresas e outras organizações, por seção da classificação de atividades

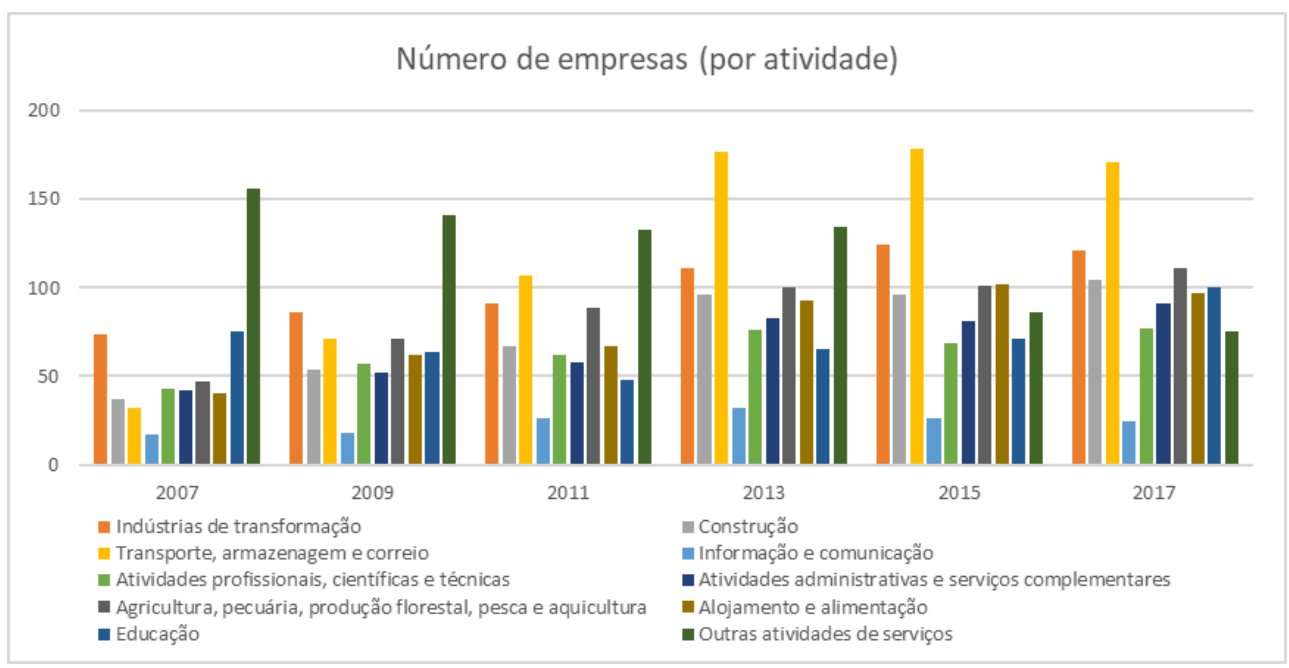

Fonte: IBGE - Cadastro Central de Empresas. Organização: BOTELHO, A. C., 2020

A dinâmica produtiva da soja trouxe profundas transformações nos usos do território da Microrregião Geográfica Gerais de Balsas, tanto no campo, quanto nas cidades. Devido à adoção de um modelo de produção altamente intensiva em capital, com elevada composição técnica e informacional em diversas etapas produtivas (preparo do solo, plantio, manejo, colheita, armazenagem), houve uma diminuição da força de trabalho diretamente empregada no campo, tanto pelo desemprego estrutural quanto pela expropriação de terras de diversas categorias de pequenos produtores, muitos dos quais migraram para os centros urbanos da região (BOTELHO, 2010), enfrentando condições precárias e degradantes de moradia e trabalho.

\section{Conclusão}

Há pelo menos quatro décadas, o grande agronegócio vem se expandindo pelo bioma Cerrado, provocando fortes alterações na organização, no uso e na regulação do território brasileiro (CASTILLO, 2015). Dentre elas, podemos citar: 1) o crescimento exponencial de monoculturas, das quais decorre o emprego intensivo de fertilizantes químicos, corretivos da acidez do solo e, sobretudo, agrotóxicos; 2) supressão indiscriminada da cobertura vegetal original, comprometimento de mananciais e contaminação e erosão de solos; 3) acirramento dos conflitos no campo e expropriação de uma grande variedade de agentes: agricultores familiares, pequenos posseiros, assentados de reforma agrária, populações tradicionais e povos ancestrais; 4) aumento da chamada circulação desnecessária (SANTOS; SILVEIRA, 2001) e alongamento dos circuitos de comercialização, dentre muitas outras.

Esse paradigma produtivo do agronegócio globalizado se consolida na região geoeconômica do, então denominado, BAMAPITO (ALVES, 2009) na década de 1990. A combinação entre diversas formas regionais, nomeadamente, a região natural dos Cerrados, sem desconsiderar sua diversidade fitofisionômica e social (RIGONATO; ALMEIDA, 2003), a institucionalização do MATOPIBA em região de planejamento e as regiões produtivas altamente especializadas, sobretudo da soja, resultou num modelo hegemônico de uso do território em favor das grandes empresas e de diversas frações 
do capital financeiro, com fácil acesso à terra e à água e apoio incondicional do Estado na apropriação de recursos públicos.

Na porção maranhense do MATOPIBA, o que se observa é uma nítida concentração da produção moderna de soja na microrregião Gerais de Balsas, onde podemos encontrar evidências que apontam para a constituição de uma Região Produtiva (SANTOS, 1985) altamente especializada, indícios de uma cidade do agronegócio (ELIAS, 2011) em formação e um gradativo processo de aumento da competitividade regional (CASTILLO; BERNARDES, 2019). Não restam dúvidas de que esta foi a porção do território maranhense mais pródiga no desenvolvimento da sojicultura intensiva. Podemos observar ainda a formação de três outras regiões produtivas secundárias ou em formação no MATOPIBA maranhense: Chapada das Mangabeiras, Chapadinha (ALMEIDA; SODRÉ; MATTOS JR, 2019) e Imperatriz, todas no bioma Cerrado.

Nada disso seria possível sem a cumplicidade e a participação direta do Estado, em suas diversas escalas territoriais. Investimentos públicos na melhoria do sistema de escoamento de grãos, sobretudo para exportação (rodovias, ferrovias, portos), benefícios fiscais para a instalação de agroindústrias ${ }^{15}$, pesquisas biotecnológicas, crédito rural oficial para os grandes empreendimentos agropecuários, investimentos em cursos técnicos e superiores voltados para o agronegócio, dentre outros.

$\mathrm{O}$ uso seletivo e corporativo do território que assim se estabelece cria um jogo de valorização e desvalorização dos lugares (SILVEIRA, 2002) que acaba por confirmar aquilo que Bacelar (2000) chamou de desintegração competitiva, ao se referir às ilhas de modernização tecnológica, privilegiadas pelos investimentos públicos e privados, coexistindo, dialeticamente, com uma vasta extensão do território e uma grande parcela da população negligenciadas pelo Estado.

\section{BIBLIOGRAFIA}

AB'SÁBER, A. N. Os domínios de natureza no Brasil: potencialidades paisagísticas. São Paulo: Ateliê Editorial, 2003

ALMEIDA, J. G.; SODRÉ, R. B.; MATTOS JR., J. S. O MATOPIBA nas Chapadas Maranhenses: impactos da expansão do agronegócio na microrregião de Chapadinha. Revista Nera, v. 22, n. 47, pp.

248-271, 2019

ALVES, V. E. L. Mobilização e modernização nos cerrados piauienses: formação territorial no império do agronegócio. 320 f. Tese (Doutorado em Geografia Humana) - Faculdade de Filosofia, Letras e Ciências Humanas, Universidade de São Paulo, São Paulo. São Paulo, 2006

ALVES, V. E. L. As novas dinâmicas socioespaciais introduzidas pelo agronegócio nos cerrados da Bahia, Maranhão, Piauí e Tocantins. In: BERNARDES, J. A.; BRANDÃO FILHO, J. B. (org.) Geografias da soja II: a territorialidade do capital. Rio de Janeiro: Arquimedes, 2009

ALVES, V. E. L. (org.). Modernização e regionalização nos cerrados do Centro-Norte do

Brasil. Rio de Janeiro: Consequência, 2015 
ASSUMPÇÃO E LIMA, D. Terra, trabalho e acumulação: o avanço da soja na região

MATOPIBA. Tese (Doutorado em Geografia). Programa de Pós-Graduação em Geografia do Instituto de Geociências da Universidade Estadual de Campinas. Campinas, 2019

BACELAR, T. Dinâmica regional brasileira nos anos noventa: rumo à desintegração competitiva? In: CASTRO, I. E.; MIRANDA, M.; EGLER, C. A. G. (org.). Redescobrindo o Brasil 500 anos depois. Rio de Janeiro: Bertrand Brasil, 2000

BECKER, B. Manual do candidato: geografia. Brasília: Fundação Alexandre de Gusmão, 2009 [substituir???]

BERNADES, J. A. Fronteiras da agricultura moderna no Cerrado Norte/Nordeste: descontinuidades e permanências. In: BERNARDES, J. A.; BRANDÃO FILHO, J. B. (org.) Geografias da soja II: a territorialidade do capital. Rio de Janeiro: Arquimedes, 2009

BORRAS Jr., S. M.; KAY, C; GÓMEZ, S.; WILKINSON, J. Land grabbing and global capitalist accumulation: key features in Latin America. Canadian Journal of Development Studies, 33:4, 402-416, 2012

BOTELHO, R. E. P. Circuito espacial de produção e círculos de cooperação da soja no Maranhão no período técnico-científico-informacional. Dissertação de mestrado apresentada ao Programa de Pós-graduação em Geografia da Universidade Federal do Rio Grande do Norte. Natal, 2010.

BRAGA, V.; CASTILLO, R. Tipologia e topologia de nós logísticos no território brasileiro: uma análise dos terminais ferroviários e das plataformas multimodais. Boletim Campineiro de Geografia, v. 3, n. 2, 2013

CASTILLO, R. Dinâmicas recentes do setor sucroenergético no Brasil: competitividade regional e expansão para o bioma Cerrado. GEOgraphia, ano 18, Dossiê Especial, 2015

CASTILLO, R.; BERNARDES, J. A. Apresentação e apontamentos teórico-metodológicos. In: BERNARDES, J. A.; CASTILLO, R. (org.). Espaço geográfico e competitividade: regionalização do setor sucroenergético no Brasil. Rio de Janeiro: Lamparina, pp.07-16, 2019

CASTILLO, R.; ELIAS, D.; PEIXINHO, D.; BÜHLER, E.-A.; PEQUENO, R.; FREDERICO, S. Regiões do Agronegócio, novas relações campo-cidade e reestruturação urbana. Revista da Associação Nacional de Pós-graduação e Pesquisa em Geografia (Anpege). p.265-288, V.12, n.18, especial GT Anpege 2016.

CASTILLO, R.; FREDERICO, S. Espaço geográfico, produção e movimento: uma reflexão sobre o conceito de circuito espacial produtivo. Sociedade \& Natureza, 22 (3): 461-474, dez. 2010a

CASTILLO, R.; FREDERICO, S. Dinâmica regional e globalização: espaços competitivos agrícolas no território brasileiro. Mercator, ano 9, n. 18, 2010b

CORRÊA, R. L. Processos, formas e interações espaciais. Revista Brasileira de Geografia, v. 61, n. 1, p. 127-134, jan-jun 2016

ELIAS, D. O meio técnico-científico-informacional e a reorganização do espaço agrário nacional. In:. MARAFON, G. J et al. (org.). Abordagens teórico-metodológicas em geografia agrária. Rio de Janeiro: EdUERJ, 2007

ELIAS, D. Agronegócio e novas regionalizações no Brasil. Revista Brasileira de Estudos Urbanos e Regionais, v. 13, n. 2, 2011 
ELIAS, D. Regiões produtivas do agronegócio: notas teóricas e metodológicas. In: BERNARDES, J. A.; SILVA, C. A.; ARRUZZO, R. C. (org.). Espaço e energia: mudanças no paradigma sucroenergético. Rio de Janeiro: Lamparina, 2013

ELIAS, D. Reestruturação produtiva da agropecuária e novas regionalizações no Brasil. In: ALVES, V.E.L. Modernização e regionalização nos cerrados do Centro-Norte do Brasil. Rio de Janeiro: Consequência Editora, pp. 25-44, 2015.

FACCIN, A. C. T. M.; CASTILLO, R. A centralidade do complexo soja na economia brasileira e a manutenção da produção agrícola extravertida: análise da soja em Mato Grosso do Sul. Geosul, v. 34, n. 71, 2019

FERREIRA, A. J. Políticas territoriais e a reorganização do espaço maranhense. 269 f. Tese (Doutorado em Geografia Humana) - Faculdade de Filosofia, Letras e Ciências Humanas. Universidade de São Paulo, São Paulo. São Paulo, 2008

FERREIRA, M. da G. A dinâmica da expansão da soja e as novas formas de organização do espaço na região de Balsas - MA. 276 f. Tese (Doutorado em Geografia) - Instituto de Geociências. Universidade Federal do Rio de Janeiro, Rio de Janeiro. Rio de Janeiro, 2008

GARAGORRY, F. L.; MIRANDA, E. E. de; MAGALHÃES, L. A. MATOPIBA: evolução recente da produção de grãos. Nota Técnica n. 9. / Campinas, SP: Embrapa Territorial / GITE, outubro 2009

GEIGER, P. P. Regionalização. Revista Brasileira de Geografia. Rio de Janeiro, v. 31, n 1, Jan/Mar, 1969

GOTTMANN, J. The Evolution of the concept of territory. Social Science Information n. 14, v. 3/4, p. 29-47, 1975

ISNARD, H. O espaço geográfico. Coimbra: Almedina, 1982

OLIVEIRA, A. U. A Amazônia e a nova geografia da produção de soja. Terra Livre, Goiânia, v.1, n. 26, p. 13-43, jan.-jun. 2006.

MIRANDA, E.; MAGALHÃES, L.; CARVALHO, C. Proposta de delimitação territorial do MATOPIBA, Nota Técnica no1, EMBRAPA, Grupo de Inteligência Territorial Estratégica (GITE), 2014. Disponível em: https://www.embrapa.br/busca-de-publicacoes/-/publicacao/1037313/propostade-delimitacao-territorial-do-matopiba

PALUDZYSZYN FILHO, E. A cultura da soja no sul do Maranhão. Balsas: EMBRAPA-CNPSo, 1995. $34 \mathrm{p}$.

RIGONATO, V. D.; ALMEIDA, M. G. de. A singularidade do Cerrado: interrelação das populações tradicionais com as fitofisionomias. Anais. VIII EREGEO - Encontro Regional de Geografia. A geografia no mundo da diversidade. Cidade de Goiás. outubro de 2003

SANO, E. E.; ROSA, R.; BRITO, J. L. S.; FERREIRA, L. G. Mapeamento da cobertura vegetal do bioma Cerrado: estratégias e resultados. Planaltina, DF: Embrapa Cerrados, 2007

SANTOS, M. Sociedade e espaço: a formação social como teoria e como método. Boletim Paulista de Geografia, n. 54, 1977

SANTOS, M. Espaço e Método. São Paulo: Nobel, 1985

SANTOS, M. Técnica, espaço, tempo: globalização e meio técnico-científico-informacional. São Paulo: Hucitec, 1994

SANTOS, M. A natureza do espaço: técnica e tempo, razão e emoção. São Paulo: Hucitec, 1996 
SANTOS, M. Por uma outra globalização: do pensamento único à consciência universal. Rio de Janeiro: Record, 2000

SANTOS, M.; SILVEIRA, M. L. O Brasil: território e sociedade: no início do século XXI. Rio de Janeiro: São Paulo, 2001

SILVEIRA, M. L. Uma globalização desnecessária, um território instável. Ciência Geográfica, ano 8 , volume I, n. 21, 2002

SOUZA, G. V. A.; PEREIRA, M. F. V. 2019. MATOPIBA: a Inteligência Territorial Estratégica (ITE) e a regionalização como ferramenta. Revista Nera, v. 22, n. 47, pp. 22-45, 2019

SOUZA, G. V. A.; SILVA, L. R. Agronegócio e dependência: uma perspectiva de análise sobre a região do MATOPIBA. Caminhos da Geografia, v. 20, n. 72, p. 149-168, 2019

XAVIER, G. L. MATOPIBA: a ocupação da nova fronteira agrícola nos quadros do padrão exportador de especialização produtiva. Confins. n. 39, 2019.

\section{NOTAS}

1. O Rio Grande do Sul possui uma área plantada maior do que a do Paraná (de mais de 300 mil hectares), mas uma quantidade produzida menor (de quase 1,5 milhão de toneladas), devido ao maior rendimento médio da produção paranaense, cuja diferença em relação ao gaúcho se aproxima de $200 \mathrm{Kg}$ por hectare (PAM-IBGE).

2. O termo "macrorregião geoeconômica" foi empregado por Geiger (1969) em 1967 para designar a divisão regional do Brasil em Amazônia, Nordeste e Centro-Sul, fundamentada em critérios naturais e, sobretudo, socioeconômicos, e que não respeitam as fronteiras entre os estados. Tal proposição serviu de inspiração para a adoção do termo "região geoeconômica" para indicar os “Cerrados Nordestinos e do Tocantins" (ALVES, 2009) como efetiva ou potencial área de modernização da agropecuária, dominada pelas grandes empresas do agronegócio, em contraste com "regiões de agricultura tradicional" (BECKER, 2009), predominantes no semiárido. A Embrapa emprega o termo "região geoeconômica" para caracterizar regiões com potencial para o desenvolvimento agropecuário, como são os casos do MATOPIBA e da AMACRO (Zona Especial para o Desenvolvimento dos estados do Amazonas, Acre e Rondônia). Disponível em: https:// www.embrapa.br/busca-de-noticias/-/noticia/47081203/reuniao-define-proposta-para-criacaoda-amacro; acesso em 27 de maio de 2021.

3. Disponível em: https://www.embrapa.br/tema-matopiba. Acesso em: 02 de março de 2021.

4. "Mapito é a nova fronteira de desenvolvimento do país". Exame, 18 de janeiro de 2013. Disponível em: https://exame.abril.com.br/economia/mapito-e-a-nova-fronteira-dedesenvolvimento-do-pais/; acesso em 18 de abril de 2020.

5. Decreto $n^{\circ} 8.447$ de 06 de maio de 2015, que dispõe sobre o Plano de Desenvolvimento Agropecuário do MATOPIBA e a criação de seu Comitê Gestor. Em 12 de novembro de 2015, foi emitida, pelo Ministério da Agricultura, Pecuária e Abastecimento, a Portaria no 244, na qual foram elencados os municípios e as unidades federativas a serem abrangidos pelo Plano de Desenvolvimento Agropecuário da região (PDA MATOPIBA).

6. Com a revogação do Comitê Gestor do PDA MATOPIBA pelo Decreto Federal 10.087 de 2019, há um comprometimento de sua operacionalidade, sem que a institucionalidade da região tenha sido revogada.

7. A delimitação territorial do MATOPIBA, estabelecida pelo Decreto № $8.447 / 2015$, abarca 31 microrregiões geográficas do IBGE, contendo 337 municípios e uma área total de 73.173.485 ha, englobando as porções oeste da Bahia (04 microrregiões, 30 municípios e 13.214.449 ha), sul e 
leste do Maranhão (15 microrregiões, 135 municípios e 23.983.346 ha), sudoeste do Piauí (04 microrregiões, 13 municípios e 8.204.588 ha) e todo o estado do Tocantins (08 microrregiões, 139 municípios e $27.772 .052 \mathrm{ha}$ ). Também é válido destacar que nesta região estão incluídos 324.326 estabelecimentos agropecuários, 46 unidades de conservação, 35 terras indígenas e 781 assentamentos de reforma agrária (MIRANDA; MAGALHÃES; CARVALHO, 2014).

8. Compreende-se região de planejamento como um recorte do espaço geográfico proposto pelo Estado, levado a dividir o território em partes para conhecê-lo melhor e intervir em seu desenvolvimento econômico e social. Trata-se de um meio e de um resultado das políticas de desenvolvimento regional.

9. Especialização regional produtiva pode ser compreendida como a manifestação geográfica da concentração da produção de um determinado ramo ou setor da economia, devida à aglomeração de fatores naturais, técnicos e/ou normativos que lhe são favoráveis, gerando vantagens competitivas às empresas que ali se instalam e às frações do espaço que assim se caracterizam.

10. Nesta proposição, de acordo com Castillo e Frederico (2010b) e Castillo (2015), compreende-se região como um recorte do espaço geográfico que se caracteriza: 1) por um elevado grau de homogeneidade de seus componentes naturais, alcançando um equilíbrio dinâmico, tal como definido por Isnard (1982) (região natural); 2) pelo compartilhamento de traços históricoculturais que se manifestam na paisagem e em hábitos, tradições, savoir-faire dentre outros, na longa duração (região histórica); 3) pela divisão de um território em partes para conhecer melhor o todo e para a proposição e execução de políticas públicas que objetivam investir em porções selecionadas de um território, como aquelas de desenvolvimento regional (região de planejamento); 4) pelo aprofundamento da divisão territorial do trabalho e a consequente especialização regional produtiva, em paralelo ao aumento de fluxos materiais e informacionais em todas as escalas (região produtiva). Essas quatro formas regionais coexistem e evoluem juntas por meio de permanentes interações complementares e contraditórias.

11. O Programa de Cooperação Nipo-Brasileira para o Desenvolvimento dos Cerrados foi criado em 1974 para tornar o Cerrado brasileiro mais produtivo, principalmente na produção de grãos como a soja.

12. A partir da proposição de Elias $(2011 ; 2013 ; 2015)$ para identificar as regiões produtivas do agronegócio (RPA), selecionamos: 1) o tema "reestruturação produtiva da agropecuária"; 2) os processos associados "mudanças das formas de uso e ocupação do espaço", "aumento do número de empresas no espaço agrícola em detrimento da agricultura camponesa" e "Mudança na base técnica dos sistemas agrícolas"; 3) as variáveis "culturas (temporárias e permanentes), tradings e agroindústrias, empresas de insumos, uso de maquinário agrícola, armazenamento, assistência técnica, uso de biotecnologias"; 4) e, finalmente, os indicadores "dados sobre produção" (área plantada e participação da área plantada no total de culturas permanentes e temporárias), quantidade de empresas, tipologia das empresas, informações e/ou dados qualitativos, informações sobre a infraestrutura".

13. O ano de 2016 foi retirado do cálculo do rendimento médio da produção de soja na microrregião Gerais de Balsas por apresentar uma cifra muito destoante $(1.313 \mathrm{Kg} / \mathrm{ha})$ da década de 2010, possivelmente por erro de contagem ou de registro da informação no IBGE.

14. O termo "crescimento vertical" significa um aumento da quantidade produzida pela elevação do rendimento médio da produção (produtividade média), ao passo que o termo "crescimento horizontal" expressa o aumento da quantidade produzida pela expansão da área plantada.

15. Portaria 84/2018, publicada no Diário Oficial do Estado do Maranhão em 08 de março de 2018. 


\section{RESUMOS}

A predominância incontestável da produção e processamento da soja nas macrorregiões CentroOeste e Sul do território brasileiro não ofusca a dinâmica acelerada, principalmente a partir da década de 2000, e as particularidades da expansão do setor nos Cerrados do Norte e Nordeste do país, recentemente institucionalizados como MATOPIBA, região de planejamento que envolve parcialmente os estados do Maranhão, Piauí e Bahia e, integralmente, o estado do Tocantins. 0 objetivo principal do artigo é identificar as regiões produtivas do agronegócio na porção maranhense do MATOPIBA, caracterizada por uma aprofundada especialização produtiva do complexo soja, cuja regulação é fortemente influenciada por agentes do agronegócio globalizado. Com base em levantamento bibliográfico e pesquisa documental e estatística, com utilização de diversas bases de dados, sobretudo do IBGE e da Embrapa Territorial, pode-se concluir que a Região Produtiva do Agronegócio da Soja de Gerais de Balsas se destaca como a mais consolidada e figura entre as mais importantes dos Cerrados do Norte e Nordeste do país. Este artigo foi motivado pelo projeto de pesquisa intitulado "Uso do território, modernizações, desigualdades sociais e questão ambiental no Maranhão" (CAPES-PROCAD Amazônia), do qual os dois primeiros autores participam.

El innegable predominio de la producción y procesamiento de la soja en las macrorregiones Centro-Oeste y Sur del territorio brasileño no ensombrece la acelerada dinámica, especialmente desde la década de 2000, y las particularidades de la expansión del sector en los Cerrados del Norte y Nordeste del país, recientemente institucionalizados como MATOPIBA, una región de planificación que involucra parcialmente a los estados de Maranhão, Piauí y Bahia y, de forma integral, al estado de Tocantins. El objetivo principal del presente trabajo se centra en la identificación de las regiones productivas agroindustriales en la porción de Maranhão que pertenece a MATOPIBA, caracterizada por una profundización de la especialización productiva del complejo de la soja, cuya regulación está fuertemente influenciada por los agentes del agronegocio globalizado. A partir de una búsqueda bibliográfica y una investigación documental y estadística, utilizando diferentes bases de datos, especialmente el IBGE y la Embrapa Territorial, se puede concluir que la Región Productiva Agroindustrial de Soja de Gerais de Balsas se destaca como la más consolidada y se ubica entre las más importantes de los Cerrados del Norte y Nordeste del país. Este artículo fue motivado por el proyecto de investigación titulado "Uso del territorio, modernizaciones, desigualdades sociales y cuestiones ambientales en Maranhão" (CAPES-PROCAD Amazônia), del cual participan los dos primeros autores.

The indisputable predominance of soy production and processing in the Midwest and South macro-regions of the Brazilian territory does not overshadow the accelerated dynamics, especially since the 2000s, and the particularities of the sector's expansion in the Cerrados of the North and Northeast of the country, recently institutionalized as MATOPIBA, a planning region that partially involves the states of Maranhão, Piauí and Bahia and, entirely, the state of Tocantins. The main purpose or this paper is to indentify the agribusiness productive regions on the Maranhão portion of MATOPIBA, characterized by a deepened productive specialization of the soybean complex, whose regulation is strongly influenced by globalized agribusiness agents. Based on bibliographical survey and documental and statistical research, using several databases, especially IBGE and Embrapa Territorial, it can be concluded that the Soybean Agribusiness Productive Region of Gerais de Balsas stands out as the most consolidated and ranks among the most important of the Cerrados in the North and Northeast of the country. This article was motivated by the research project entitled "Use of territory, modernizations, social inequalities 
and environmental issues in Maranhão" (CAPES-PROCAD Amazônia), in which the first two authors participate.

La prédominance incontestable de la production et de la transformation du soja dans les macrorégions Centre-Ouest et Sud du territoire brésilien n'éclipse pas la dynamique accélérée, surtout depuis les années 2000, et les particularités de l'expansion de la filière dans les Cerrados du Nord et du Nord-Est du pays, récemment institutionnalisée sous le nom de MATOPIBA, une région de planification qui implique partiellement les États de Maranhão, Piauí et Bahia et, entièrement, l'État de Tocantins. Le présent article a pour principal objectif d'identifier les régions produtives agroalimentaires dans l'état de Maranhão dans le cadre du MATOPIBA, caractérisée par une spécialisation profonde de la production du complexe soja, dont la régulation est fortement influencée par les agents de l'agrobusiness mondialisé. Sur la base d'une enquête bibliographique et d'une recherche documentaire et statistique, utilisant plusieurs bases de données, notamment IBGE et Embrapa Territorial, on peut conclure que la Région Productive Agroalimentaire du Soja de Gerais de Balsas se distingue comme la plus consolidée et se classe parmi les plus importantes des Cerrados du Nord et du Nord-Est du pays. Cet article a été motivé par le projet de recherche intitulé "Usage du territoire, modernisations, inégalités sociales et enjeux environnementaux dans le Maranhão” (CAPES-PROCAD Amazônia), auquel participent les deux premiers auteurs.

\section{ÍNDICE}

Mots-clés: MATOPIBA, Biome Cerrado du Maranhão, filière du soja, spécialisation productive régionale, région productive du secteur agroalimentaire

Palavras-chave: MATOPIBA, Cerrado maranhense, complexo soja, especialização regional produtiva, região produtiva do agronegócio.

Keywords: MATOPIBA, Cerrado of Maranhão, soybean complex, productive regional specialization, productive region of agribusiness

Palabras claves: MATOPIBA, Cerrado de Maranhão, soja, especialización regional productiva, región de producción agroindustrial

\section{AUTORES}

\section{RICARDO CASTILLO}

Universidade Estadual de Campinas (UNICAMP). Instituto de Geociências. Docente. Bolsista de Produtividade em Pesquisa do CNPq. E-mail: castillo@unicamp.br.

\section{ADIELSON CORREIA BOTELHO}

Universidade Estadual de Campinas (UNICAMP). Instituto de Geociências. Doutorando do Programa de Pós-Graduação em Geografia da Unicamp e Bolsista da Capes. E-mail: adielsonbotelho@hotmail.com

\section{MATHEUS DEZIDÉRIO BUSCA}

Universidade Estadual de Campinas (UNICAMP). Instituto de Geociências. Mestrando do Programa de Pós-Graduação em Geografia da Unicamp. E-mail: matheusdbusca@gmail.com 